\title{
SCIDOC
}

\author{
International Journal of Dentistry and Oral Science (IJDOS) \\ ISSN: 2377-8075
}

\section{Dentists Preference Of Brushing Technique Taught To Children With Primary Dentition}

Research Article

Navya Khanna ${ }^{1}$, Vignesh Ravindran ${ }^{2 *}$

${ }^{1}$ Saveetha Dental College and Hospitals, Saveetha Institute of Medical and Technical Sciences (SIMATS), Saveetha University, Chennai- 77, India. ${ }^{2}$ Senior Lecturer, Department of Pediatric and Preventive Dentistry, Saveetha Dental College and Hospitals, Saveetha Institute of Medical and Technical Sciences [SIMATS], Saveetha University, Chennai- 77, India.

\section{Abstract}

Introduction: Dentists play a vital role in the primary prevention of dental problems in young patients through preventive treatments, risk assessment and anticipatory guidelines for parents regarding oral development, caries prevention and overall oral health. The maintenance of primary dentition is important to guide the eruption of primary teeth. Proper brushing technique is vital to obtain efficient plaque control and decrease caries.

Aim: To evaluate the commonly used brushing technique by the dentist in children with primary dentition.

Materials \& Methods: He study was performed as a retrospective study under a university setting in the outpatient department of Pediatric and Preventive Dentistry. Data was collected by reviewing patient records and analysed data of 56000 patients between June 2020 to Feb 2021. Verification of the data was done with the presence of additional reviewers. Data of brushing techniques used in pediatric dentistry was collected from the patient management records. Patients upto the age of 5 were shortlisted. It was tabulated in excel and analysed using SPSS software.

Results: Gender distribution was $60.5 \%$ males and 39.5\% females. Most commonly taught technique was Fones $(95.8 \%)$ and Bass (2.4\%). Fones technique was more commonly taught for both male and female children, which was not statistically significant. $(\mathrm{p}>0.05)$.

Conclusion: Within the limitations of the present study, Fones brushing technique was the most preferred technique taught by dentists in the primary dentition with male predominance.

Keywords: Primary Dentition; Primary Teeth; Dental Plaque.

\section{Introduction}

Dental caries are an oral health condition that results from plaque accumulation on the tooth surface, converting sugar found in food and drinks into acid, consequently resulting in tooth damage. It is considered a major health problem affecting 2.4 billion people worldwide in the year 2010 [1]. It is linked to poor oral hygiene, diet, and infrequent dental visits [2]. Dental caries are a widespread health problem among children [3], prevailing around 60-90\% [4]. Moreover, dental caries influence a child's quality of life psychologically [5] exposing him/her pain and discomfort at an early age. Children with caries were found to be 1.3 times more likely to experience oral health-related impact on the quality of their lives [6].
Despite being largely preventable, dental caries remains a significant health problem among children in both developing and industrialised nations $[7,8]$. Children with caries have an increased risk of developing subsequent caries in both the primary and permanent dentitions $[9,10]$ underscoring the importance of promoting thorough plaque removal early in life.

Dental plaque plays an important role in the aetiology of dental caries, gingivitis and its progression to periodontitis. Regular removal of dento-gingival plaque is crucial for the maintenance of periodontal health. Mechanical cleaning is recognised to be potentially useful in controlling supra gingival plaque, but expecting that each individual will maintain a good standard of oral hygiene

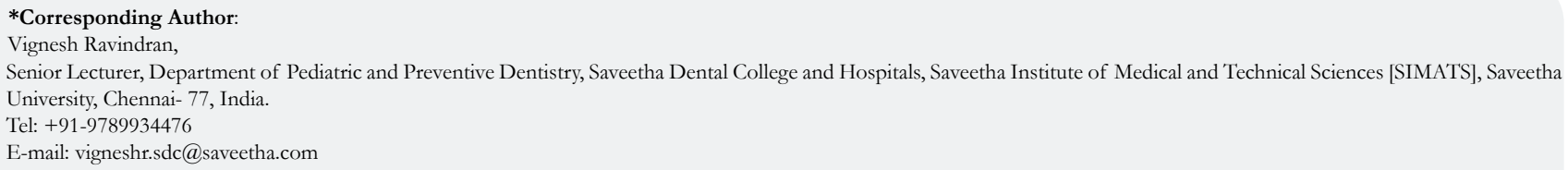

Copyright: Vignesh Ravindran ${ }^{\circ}$ 2021. This is an open-access article distributed under the terms of the Creative Commons Attribution License, which permits unrestricted use, distribution and reproduction in any medium, provided the original author and source are credited. 
seems to be beyond most people's capabilities.

Tooth brushing is the most widely accepted mechanical means of plaque control due to its effectiveness, convenience, as well as low cost. Tooth brushing is the primary oral health activity for young children and a well known tool in oral care $[11,12]$. Effective tooth brushing helps in the management of dental caries and periodontal disease, which can cause pain, eating difficulties, malnutrition, esthetic problems, reducing self estimation, and consequently reducing the quality of life. Bacterial plaque serves as a principal etiologic factor for dental caries and gingivitis. Plaque removal from dental surfaces using proper brushing technique may help in the management of both caries and periodontal problems $[13,14]$.

The various tooth brushing techniques practiced are Roll or Modified Stillman, Stillman's, Charters, Bass, Modified Bass, Fones, Leonard, and Scrub. Modified Bass technique was reported to be the most effective brushing technique followed by Horizontal Scrub technique, while the least effective was Fones. This was based on improved plaque control and reduced gingival inflammation with modified Bass and horizontal scrub techniques compared to others. However, these findings were based on a small study population and short follow up periods. Modified Bass technique was also reported to be superior in reducing supragingival plaque than Normal tooth brushing practices. An optimal reduction in plaque with adequate protection of the oral tissues against mechanical trauma is achieved by manual tooth brushing with the use of Modified Bass technique.

The most efficient method in mechanical plaque control is tooth brushing that results in a significant decrease in plaque. Various studies conducted on teaching brushing in children have reported the use of the right technique to the age of the child is important (15). Effective plaque removal in young children depends on their level of motor skill development and learning sequences of coordinated muscular movement. It has been generally known that tooth brushing by young children is inefficient; this might be due to lack of motivation and poor manual dexterity at this age. Thus, oral hygiene education should be taught to children according to the development of a child's cognitive skills. Instructions should be given according to the child's readiness for tooth brushing and must also include proper training and regular reinforcement [16, $17]$.

Proper brushing techniques with proper lecture should be delivered to the patients to obtain efficient plaque control and to decrease the incidence of caries and periodontal problems. Our team has extensive knowledge and research experience that has translate into high quality publications [18-30, 31-37]. The aim of this study was to evaluate the common bushing technique advised by dentists during the primary dentition stage.

\section{Materials and Methods}

This study is a retrospective study conducted in a University setting. The ethical approval was obtained from the Institution Ethical Review Board Approval. The study involved two people. The required data of patients were obtained from the cases from June 2019 to February 2021 and reviewed. Informed consent was obtained from the parents or guardian regarding usage of the clinical data for research purposes.

A total number of 500000 cases were reviewed. The inclusion criteria for the study were children with primary dentition, that is, children under the age of 5 years. The exclusion criteria were children under specific care, incomplete data and incomplete photographic evidence.

Digital entry of clinical examination, intraoral photographs of the oral cavity and the treatment procedure were assessed. The data collected (digital entry and intraoral photographs) was verified by an external additional reviewer. Sampling bias was minimised by doing simple random sampling. There was no resolution of conflict. The censored data was discarded. If any error in data entry or patient details or clinical data were noticed, that case sheet was excluded from the study.

The tabulated data from the Excel was imported to SPSS for statistical analysis. Descriptive statistics was performed. Comparison with gender of patients using chi-square test was done. The software used was SPSS (version 22, IBM software, Chicago). The independent variable was age and the dependent variables were type of brushing technique and gender.

\section{Results}

Final study sample consisted of 180 patients belonging to an age group of below 5 years, that is, children with complete primary dentition were taken for the study. Children at the age of 5 were maximum (46.1\%). The mean age of the children was four years (Graph 1). Based on the gender of the patients $60.5 \%$ were males and 39.5\% were females (Graph 2). The most common brushing technique was Fones technique $(95.8 \%)$, followed by Bass technique $(2.4 \%)$, followed by modified Bass technique at $1.2 \%$. The least recommended was Roll technique (0.6\%) (Graph 3). Based on comparison of the gender to the techniques taught to children, Fones technique was more commonly recommended for both male and female children, which was not statistically significant. $(p=0.389)($ Graph 4).

\section{Graph 1. Bar graph depicting age distribution of children taken for the study. Maximum percentage of children receiving brushing technique instructions were of the age of five (orange color $-46.1 \%$ ), followed by age 4 (red - 37\%).}

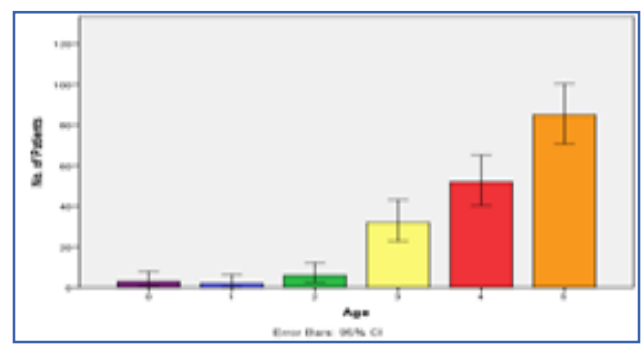


Graph 2. Bar graph depicting gender distribution of children taken for the study. $60.5 \%$ were males (green) and $39.5 \%$ were females (blue).

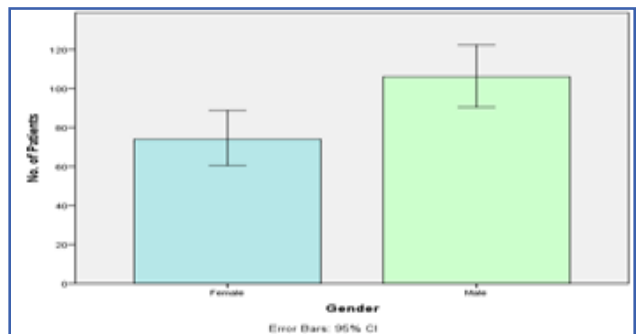

Graph 3. Bar graph depicting the distribution of brushing techniques advised to children taken for the study. The most common brushing technique was Fones technique (green - 95.8\%), followed by Bass technique (blue - $2.4 \%$ ), followed by modified Bass technique (yellow - 1.2\%). The least recommended was Roll technique (violet $-0.6 \%$ ).

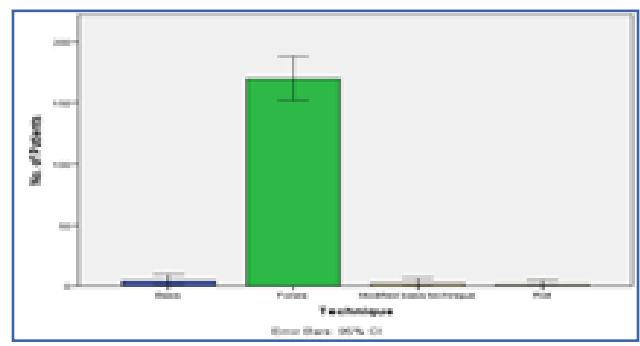

Graph 4: Bar graph depicting comparison of brushing technique taught based on gender of the children. Fones technique (green) was more commonly recommended for both male and female children, which was not statistically significant. (Pearson chi square test, $\mathrm{p}=0.389$-not significant) There is no difference in the most prevalent type of brushing technique taught by the dentist based on the gender of the children.

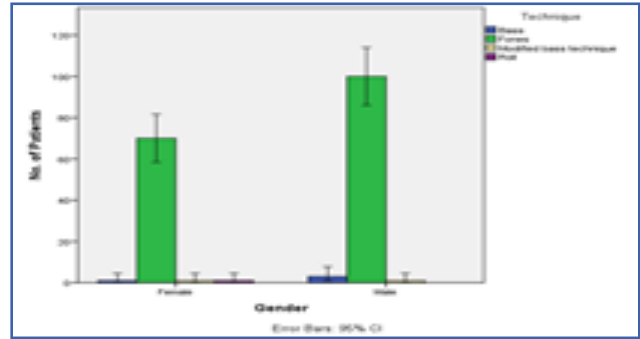

\section{Discussion}

Our findings are in line with that of [38], who compared remaining plaque after brushing with Bass and Fones technique and found the Fones technique to be superior. It is interesting that their participants were dental students and Dental staff or persons who should know all the techniques pretty well. Some other studies are less conclusive, as they lack control groups and standard sized instructions. Furthermore, gingivitis as an indicator of habitual oral hygiene is not assured in the studies nor are oral hygiene skills used as a premiere of successful hygiene.

The anti-plaque efficacy of Fones technique has also been well documented. A six-week follow-up study showed significant difference in plaque scores after using Fones technique of brushing. As opposed to modified Bass technique, Fones technique has showed significant difference in the previously mentioned study by Hernacke.

Our study results provide Fones to be the dentist preference but previous literature tilted in favour of modified Bass technique. A study showing the comparison of different tooth brushing techniques for the effectiveness of plaque control, the modified Bass technique was found to be effective. Bergenholtz et al., [39] compared the Bass method with three other techniques- the Rolls method, the Circular Scrub and Horizontal scrub, showing that Bass method was superior to others. This is more effective in removing supragingival plaque from the surface.

One of the reasons for this observation could probably be due to the Hawthorne effect which shows the increased use of new brushing technique (which is modified bass $\&$ fones). Since Fones was also a new technique to the participants, instructions were advised and taught, but there was no significant difference observed. The probable reason might be ineffective interdental plaque removal. Our results are in consensus with Srivatsava et al., [40], who recommended Fones technique for children with mixed dentition. Atarbashi et al., [41] in his review reveals that Fones technique was recommended for children commonly.

The advantage of this study was that it had easy access, large availability of data, flexibility in data collection, less expenditure and maximum internal validity. It was also used to identify any mistakes as a brushing technique advised. The limitation of this study was that it had reduced sample size and minimum external validity. It was an unicentred study with a geographic limitation. The future scope was that it should be conducted as a multicentered study with an extent in the geographic limitation. 


\section{Conclusion}

Within the limits of the study, Fones technique was recommended mostly for both male and female children with primary dentition. Proper brushing technique with proper education should be delivered to the patient to obtain efficient plaque control to decrease the incidence of caries and their problems.

\section{Acknowledgement}

The authors are thankful to the Department of Pediatric Dentistry, Saveetha Dental College, Saveetha Institute of Medical and Technical science, Saveetha University for providing a platform in expressing their knowledge.

\section{Source of Funding}

The present project was funded by

- Saveetha Dental College, Saveetha Institute of Medical and Technical Sciences, Saveetha University and

- Deepak Bearing Enterprises, New Delhi.

\section{References}

[1]. Kassebaum NJ, Bernabé E, Dahiya M, Bhandari B, Murray CJ, Marcenes W. Global burden of untreated caries: a systematic review and metaregression. J. Dent. Res. 2015 May;94(5):650-8.

[2]. Mulu W, Demilie T, Yimer M, Meshesha K, Abera B. Dental caries and associated factors among primary school children in Bahir Dar city: a crosssectional study. BMC Res Notes. 2014 Dec 23;7:949.Pubmed PMID: 25540044.

[3]. Fontana M, Young DA, Wolff MS. Evidence-based caries, risk assessment, and treatment. Dent. Clin. N. Am. 2009 Jan 1;53(1):149-61.

[4]. Nota A, Caruso S, Cantile T, Gatto R, Ingenito A, Tecco S, et al. Socioeconomic Factors and Oral Health-Related Behaviours Associated with Dental Caries in Preschool Children from Central Italy (Province of Ascoli Piceno). Biomed Res Int. 2019 Dec 23;2019:7981687.Pubmed PMID: 31930137.

[5]. Elidrissi SM, Naidoo S. Prevalence of dental caries and toothbrushing habits among preschool children in Khartoum State, Sudan. Int Dent J. 2016 Aug;66(4):215-20.Pubmed PMID: 27061284

[6]. Chen KJ, Gao SS, Duangthip D, Lo ECM, Chu CH. Prevalence of early childhood caries among 5-year-old children: A systematic review. J Investig Clin Dent. 2019 Feb;10(1):e12376.Pubmed PMID: 30499181.

[7]. Anil S, Anand PS. Early childhood caries: prevalence, risk factors, and prevention. Front Pediatr. 2017 Jul 18;5:157.

[8]. Çolak H, Dülgergil ÇT, Dalli M, Hamidi MM. Early childhood caries update: A review of causes, diagnoses, and treatments. J Nat Sci Biol Med. 2013 Jan;4(1):29-38

[9]. Milsom KM, Blinkhorn AS, Tickle M. The incidence of dental caries in the primary molar teeth of young children receiving National Health Service funded dental care in practices in the North West of England. Br Dent J. 2008 Oct 11;205(7):E14; discussion 384-5.Pubmed PMID: 18849940.

[10]. Prasai Dixit L, Shakya A, Shrestha M, Shrestha A. Dental caries prevalence, oral health knowledge and practice among indigenous Chepang school children of Nepal. BMC Oral Health. 2013 May 14;13:20.Pubmed PMID: 23672487

[11]. Petti S, Cairella G, Tarsitani G. Rampant early childhood dental decay: an example from Italy. J Public Health Dent. 2000 Summer;60(3):159-66.Pubmed PMID: 11109213

[12]. Tsutsui A, Yagi M, Horowitz AM. The prevalence of dental caries and fluorosis in Japanese communities with up to $1.4 \mathrm{ppm}$ of naturally occurring fluoride. J Public Health Dent. 2000 Summer;60(3):147-53.Pubmed PMID: 11109211

[13]. Philip N, Suneja B, Walsh LJ. Ecological approaches to dental caries prevention: paradigm shift or shibboleth?. Caries Res. 2018;52(1-2):153-65.

[14]. Rosema NA, Hennequin-Hoenderdos NL, Berchier CE, Slot DE, Lyle DM, van der Weijden GA. The effect of different interdental cleaning devices on gingival bleeding. J Int Acad Periodontol. 2011 Jan 1;13(1):2-10.

[15]. Benadof D, Polk D, Documet P. Stages and transitions in the development of tooth brushing skills in children of Mexican immigrant families: a qualitative study. J Public Health Dent. 2015 Fall;75(4):337-42.Pubmed PMID: 26079473.

[16]. Unkel JH, Fenton SJ, Hobbs Jr G, Frere CL. Toothbrushing ability is related to age in children. ASDC J Dent Child. 1995 Sep 1;62(5):346-8.

[17]. Williford JW, Muhler JC, Stookey GK. Study demonstrating improved oral health through education. J Am Dent Assoc. 1967 Oct 1;75(4):896-902.

[18]. Subramanyam D, Gurunathan D, Gaayathri R, Vishnu Priya V. Comparative evaluation of salivary malondialdehyde levels as a marker of lipid peroxidation in early childhood caries. Eur J Dent. 2018 Jan-Mar;12(1):67-70. Pubmed PMID: 29657527.

[19]. Ramadurai N, Gurunathan D, Samuel AV, Subramanian E, Rodrigues SJ. Effectiveness of $2 \%$ Articaine as an anesthetic agent in children: randomized controlled trial. Clin Oral Investig. 2019 Sep;23(9):3543-50.

[20]. Ramakrishnan M, Dhanalakshmi R, Subramanian EMG. Survival rate of different fixed posterior space maintainers used in Paediatric Dentistry - A systematic review. Saudi Dent J. 2019 Apr;31(2):165-172.Pubmed PMID: 30983825.

[21]. Jeevanandan G, Thomas E. Volumetric analysis of hand, reciprocating and rotary instrumentation techniques in primary molars using spiral computed tomography: An in vitro comparative study. Eur J Dent. 2018 JanMar;12(1):21-26.Pubmed PMID: 29657521.

[22]. Princeton B, Santhakumar P, Prathap L. Awareness on Preventive Measures taken by Health Care Professionals Attending COVID-19 Patients among Dental Students. Eur J Dent. 2020 Dec;14(S 01):S105-S109.Pubmed PMID: 33321549.

[23]. Saravanakumar K, Park S, Mariadoss AVA, Sathiyaseelan A, Veeraraghavan VP, Kim S, et al. Chemical composition, antioxidant, and anti-diabetic activities of ethyl acetate fraction of Stachys riederi var. japonica (Miq.) in streptozotocin-induced type 2 diabetic mice. Food Chem Toxicol. 2021 Sep;155:112374.Pubmed PMID: 34186120.

[24]. Wei W, Li R, Liu Q, Seshadri VD, Veeraraghavan VP, Mohan SK, et al. Amelioration of oxidative stress, inflammation and tumor promotion by Tin oxide-Sodium alginate-Polyethylene glycol-Allyl isothiocyanate nanocomposites on the 1,2-Dimethylhydrazine induced colon carcinogenesis in rats. Arab. J. Chem. 2021 Jun 3;14(8):103238.

[25]. Gothandam K, Ganesan VS, Ayyasamy T, Ramalingam S. Antioxidant potential of theaflavin ameliorates the activities of key enzymes of glucose metabolism in high fat diet and streptozotocin - induced diabetic rats. Redox Rep. 2019 Dec;24(1):41-50.Pubmed PMID: 31142215.

[26]. Su P, Veeraraghavan VP, Krishna Mohan S, Lu W. A ginger derivative, zingerone-a phenolic compound-induces ROS-mediated apoptosis in colon cancer cells (HCT-116). J Biochem Mol Toxicol. 2019 Dec;33(12):e22403. Pubmed PMID: 31714660.

[27]. Mathew MG, Samuel SR, Soni AJ, Roopa KB. Evaluation of adhesion of Streptococcus mutans, plaque accumulation on zirconia and stainless steel crowns, and surrounding gingival inflammation in primary molars: randomized controlled trial. Clin Oral Investig. 2020 Sep;24(9):3275-3280.Pubmed PMID: 31955271.

[28]. Sekar D, Johnson J, Biruntha M, Lakhmanan G, Gurunathan D, Ross K. Biological and clinical relevance of microRNAs in mitochondrial diseases/ dysfunctions. DNA Cell Biol. 2020 Aug 1;39(8):1379-84.

[29]. Velusamy R, Sakthinathan G, Vignesh R, Kumarasamy A, Sathishkumar D, Priya KN, et al. Tribological and thermal characterization of electron beam physical vapor deposited single layer thin film for TBC application. Surf Topogr: Metrol Prop. 2021 Jun 24;9(2):025043.

[30]. Aldhuwayhi S, Mallineni SK, Sakhamuri S, Thakare AA, Mallineni S, Sajja R, et al. Covid-19 Knowledge and Perceptions Among Dental Specialists: A Cross-Sectional Online Questionnaire Survey. Risk Manag Healthc Policy. 2021 Jul 7;14:2851-2861.Pubmed PMID: 34262372.

[31]. Sekar D, Nallaswamy D, Lakshmanan G. Decoding the functional role of long noncoding RNAs (lncRNAs) in hypertension progression. Hypertens Res. 2020 Jul;43(7):724-725.Pubmed PMID: 32235913.

[32]. Bai L, Li J, Panagal M, M B, Sekar D. Methylation dependent microRNA $1285-5$ and sterol carrier proteins 2 in type 2 diabetes mellitus. Artif Cells Nanomed Biotechnol. 2019 Dec;47(1):3417-3422.Pubmed PMID: 31407919.

[33]. Sekar D. Circular RNA: a new biomarker for different types of hypertension. Hypertens Res. 2019 Nov;42(11):1824-5.

[34]. Sekar D, Mani P, Biruntha M, Sivagurunathan P, Karthigeyan M. Dissecting the functional role of microRNA 21 in osteosarcoma. Cancer Gene Ther. 2019 Jul;26(7-8):179-182.Pubmed PMID: 30905966.

[35]. Duraisamy R, Krishnan CS, Ramasubramanian H, Sampathkumar J, Mariappan S, Navarasampatti Sivaprakasam A. Compatibility of Nonoriginal Abutments With Implants: Evaluation of Microgap at the Implant-Abutment Interface, With Original and Nonoriginal Abutments. Implant Dent. 2019 Jun;28(3):289-295.Pubmed PMID: 31124826. 
[36]. Parimelazhagan R, Umapathy D, Sivakamasundari IR, Sethupathy S, Ali D, Kunka Mohanram R, et al. Association between Tumor Prognosis Marker Visfatin and Proinflammatory Cytokines in Hypertensive Patients. Biomed Res Int. 2021 Mar 16;2021:8568926.Pubmed PMID: 33816632.

[37]. Syed MH, Gnanakkan A, Pitchiah S. Exploration of acute toxicity, analgesic, anti-inflammatory, and anti-pyretic activities of the black tunicate, Phallusia nigra (Savigny, 1816) using mice model. Environ Sci Pollut Res Int. 2021 Feb;28(5):5809-5821.Pubmed PMID: 32978735.

[38]. KINOSHITA S, ARAI T, URAGUCHI R. Abrasive properties of commonly used dentifrices. Bull Tokyo Med Dent Univ. 1979;26(3):225-42.
[39]. Bergenholtz A, Gustafsson LB, Segerlund N, Hagberg C, Östby PN. Role of brushing technique and toothbrush design in plaque removal. European Journal of Oral Sciences. 1984 Aug;92(4):344-51.

[40]. Srivastava N, Gupta G, Rana V. A comparative evaluation of efficacy of different teaching methods of tooth brushing in children contributors. J. oral hyg. health. 2013 Dec 25:1-4.

[41]. Atarbashi-Moghadam F, Atarbashi-Moghadam S. Tooth brushing in children. J. dent. mater. tech. 2018;7(4):181-4. 